\title{
educação

\section{Elementos da fenomenologia como uma das possibilidades de compreender o jogo como um movimento humano significativo}

\author{
António Camilo Teles Nascimento Cunha \\ Universidade do Minho, Portugal
}

\author{
Aguinaldo Cesar Surdi", Danieli Alves Pereira \\ MARQUES ${ }^{\text {III }}$ \\ Universidade Federal de Santa Catarina, Brasil \\ ELENOR KunZ \\ Universidade Federal de Santa Maria, Brasil \\ Evando Carlos Moreirav \\ Universidade Federal de Mato Grosso, Brasil
}

\begin{abstract}
O presente ensaio tem como objetivo refletir sobre o Jogo como uma das dimensões do lúdico - a par do brincar e do competir. A reflexão vai fazer o elogio ao Jogo como um fim em si mesmo, contrariando a ideia do Jogo como um meio, um instrumento ao serviço de modelos teóricos e didáticos. O Jogo é capaz de emprestar a quem joga um movimento humano significativo, fundado a partir da concepção dialógica do movimento. Neste sentido serão apresentados alguns apontamentos que tornam o Jogo como parte essencial da Educação Física (e da educação em geral) e do movimento humano significativo; dentre eles, podemos citar a subjetividade, a criatividade, o sonho, a vontade, a possibilidade, a liberdade, ... como constituintes do ser humano.
\end{abstract}

Palavras-chave: Jogo; Movimento humano significativo; Subjetividade; Lúdico

\section{IN T RODUÇ̃̃ O}

Por isso a estética de Kant, sem renunciar à razão, nem ao sentimento, aos quais confere um estatuto essencial no juízo do gosto, orienta-se resolutamente em direção do barroco, pelo menos enquanto essa arte do excesso consegue conter-se nos limites do bom gosto e assim conservar uma relação satisfatória (para o sentimento) com as ideias (da razão). (Ferry, 1995, p. 154)

Tal como o gosto, discorrer sobre o Jogo, tendo em vista a complexidade que envolve o tema, apresenta-se como uma pretensão marcada pela ousadia, principalmente quando se procura creditar ao Jogo a sua função de não utilidade e esteticidade imediata, em que se 
busca a preservação dos seus aspectos estéticoexpressivos. Isso porque são raras as incursões sobre o tema do Jogo que conseguem fugir aos ditames da lógica produtivista da sociedade industrial e, mais recentemente, da cobrança subtil, invasiva e sedutora com que os jogos eletrônicos "invadem as mentes... e corpos" de crianças, adolescentes e jovens.

Nesses termos, é possível considerar a escola como instituição, entre outras, que foi criada para desenvolver o processo de socialização das novas gerações, como largamente conservadora, na medida em que aciona mecanismos capazes de assegurar "a reprodução social e cultural como requisito para a sobrevivência mesma da sociedade" (Gómez, 1998, p. 14).

Assim, fica evidente que, para os autores e para as correntes da sociologia da educação, os objetivos-funções básicos e prioritários da socialização dos educandos na escola são: a) prepará-los para serem absorvidos no mundo do trabalho; b) a formação do cidadão para sua intervenção na vida pública.

Neste contexto, Gómez (1998) vai sugerir duas funções basilares da socialização da escola - quer na sua dimensão externa como interna. Sobre a primeira:

Desde as correntes funcionalistas até a teoria da correspondência, passando pela teoria do capital humano, do enfoque credencialista ou das diferentes posições marxistas e estruturalistas, todos, ainda que com importantes matizes diferenciais, concordam em admitir que, ao menos desde o surgimento das sociedades industriais, a função principal que a sociedade delega e encarrega à escola é a incorporação futura ao mundo do trabalho. (p. 14)

Quanto à segunda:

A escola deve constituir-se como um lócus de aprendizagem e cultura onde se situa uma práxis para a vida ativa. A escola como exercício e preparação para os direitos cívicos e éticos pela participação assente numa cidadania da ação crítica e reflexiva, "através de normas de convivência que compõem o tecido social da comunidade humana”. (p. 15)

Apesar das evidências (teóricas e empíricas) do caráter reprodutor da instituição escolar, a escola tem paulatinamente convocado uma certa autonomia que, centrando-se nas forças internas (inovadoras, diferentes, criativas) contidas na cultura escolar, consegue mitigar o processo de reprodução conservadora da cultura dominante.

Acreditar nos movimentos internos das escolas (seus atores), como movimentos/forças produtoras de cultura, faz todo o sentido, pois socializar humanizando possibilita à escola exercer sua função educativa.

A função educativa ultrapassa, vai mais além da reprodução, pelo menos teoricamente. A mesma tensão dialética que aparece em qualquer formação social, entre tendências conservadoras que se propõem garantir a sobrevivência mediante a reprodução do status quo e das aquisições históricas já consolidadas (socialização) e as correntes renovadoras que impulsionam a mudança, o progresso e a transformação, como condição também de sobrevivência e enriquecimento da condição humana (humanização), acontece de forma específica e singular na escola. (Gómez, 1998, p. 21)

Já é possível a afirmação de que a Educação Física procura legitimar-se enquanto área de conhecimento que tem um espaço nos currículos escolares, com um corpo de conhecimento reconhecidamente consolidado, com o objetivo de, para além da conservação (a memória) de conhecimento e cultura, ser também produtora e criadora de cultura. Preservar e criar são, assim, pilares da Educação Física que dão o seu contributo na construção do ser humano, buscando a formação da sua personalidade e da 
sua participação ativa na sociedade.

Não obstante essa preocupação de constituir a sua legitimidade, frente às disciplinas já consolidadas na escola/currículo e perante os seus professores, a Educação Física tornouse uma disciplina no sistema escolar da modernidade, mas parece faltar-lhe ainda a função e missão específica nesse sistema. A Educação Física trata do movimento, do corpo e da cultura - missão ampla e profunda - e por isso, não pode ser o "patinho feio" do currículo, da escola e da educação. A Educação Física, nas suas diversas dimensões - brincar, jogar, competir, artes, cultura, desporto, dança, etc.-, é tão importante como as disciplinas já consolidadas do ler, escrever e contar, agora acrescentada com as novas linguagens da técnica.

Por exemplo, no Brasil, a necessidade de reconhecimento da Educação Física como um componente curricular, legal, mas não necessariamente legítimo, instaurou-se a partir da Lei $n^{\circ}$ 9394/96. Contudo, esta suscitou questões que são debatidas com frequência no contexto educacional, ou seja:

Como conciliar o "discurso" sobre a cultura corporal de movimento e uma "ação pedagógica com ela", ou ainda, como não cair na tentação e desviar-se do "fazer com" para o "falar de" na implementação de propostas de Educação Física escolar? (Moreira \& Grunennvaldt, 2016, p. 70)

Entende-se, portanto, a assertiva de Charlot (2009) quando diz que "ainda bem que a Educação Física não é uma disciplina como as demais." (p. 243).

Em Portugal, por seu lado, a Educação Física está presente no currículo escolar de forma sistematizada a partir do $5^{\circ}$ ano de escolaridade ( $2^{\circ}$ Ciclo do Ensino Básico) até ao $12^{\circ}$ ano (Ensino Secundário), contando a classificação final para a entrada na universidade. No entanto a Educação Física (Expressão Físico-Motora) também surge nos textos curriculares do $1^{\circ} \mathrm{Ciclo}$ do Ensino Básico (6-10 anos de escolaridade). Contudo, neste ciclo, como é lecionada por um professor generalista, muitas vezes a Educação
Física não é tão evidente ou atraente. Este facto tem origem em questões formativas e culturais desses professores.

Assim, este texto procura apresentar o Jogo como um dos grandes conteúdos da Educação Física escolar - capaz de estimular a memória e a criação do novo, dando à própria Educação Física e à Educação um sentido de experiência vivida no movimento e na cultura. Neste envolvimento procura-se elevar o Jogo como um dado do enriquecimento da condição humana (dos educandos), com ênfase na sua função educativa.

Discorre-se, em seguida, sobre o movimento humano significativo, fundado a partir da conceção dialógica de movimento. Por fim, traçam-se alguns apontamentos que tornam o Jogo uma parte essencial da Educação Física e do movimento humano significativo.

\section{O Jogo e A EduCaÇão Física}

Conforme Kunz (1995), a Educação Física (no Brasil), historicamente, vem utilizando práticas corporais, social e culturalmente construídas, como ginástica, desporto, dança, jogos e lutas. De entre essas manifestações da cultura corporal de movimento ou cultura de movimento, o desenvolvimento das modalidades desportivas tem sido amplamente privilegiado nos planeamentos da Educação Física, previstos, inclusive, nas próprias legislações oficiais. Em Portugal, a dimensão desportiva também está presente de forma saliente nos currículos, bem como na ação pedagógica.

O Jogo tem na sua essência (jogo como um fim) dinâmicas que antecedem as suas dimensões didáticas, pedagógicas e culturais. Este potencial parece que não tem sido utilizado nas aulas de Educação Física com a frequência de um conteúdo que se basta por si mesmo. Ele tem sido usado, geralmente, como meio para a aprendizagem de outros conteúdos, tornandose, portanto, um instrumento metodológico, utilizado habitualmente para facilitar a aprendizagem do desporto, ou seja, a condição 
do Jogo se apresentar de forma utilitarista e instrumental.

No entanto, é fundamental entender que as práticas que envolvem jogos e brincadeiras como conteúdos das aulas de Educação Física compõem um conjunto de possibilidades que ampliam a perceção e a interpretação da realidade. É possível, ainda, que os professores de Educação Física, sem se aperceberem disso, atribuam insignificância ao conteúdo Jogo, tendo em vista que estão marcados por uma leitura que o Jogo deve estar a serviço de um trabalho produtivo. Como temos vindo a referir, o jogo é um fim em si. Traz consigo a dor e o prazer, o cansaço e a leveza, a tristeza e a alegria, o sofrimento e a satisfação, etc., que se constituem como manifestações da profundidade humana.

$\mathrm{Na}$ Educação Física, e na educação em geral, o Jogo faz a síntese entre as dimensões fenomenológicas e racionais. Este facto está presente nos próprios textos legais. Por exemplo, os Parâmetros Curriculares Nacionais (PCN) (Brasil, 1998) estabelecem:

O desenvolvimento moral do indivíduo, que resulta das relações entre a afetividade e a racionalidade, encontra no universo da cultura corporal um contexto bastante peculiar, no qual a intensidade e a qualidade dos estados afetivos experimentados corporalmente nas práticas da cultura de movimento literalmente afetam as atitudes e decisões racionais. (p. 34)

O Jogo como elemento de um plano maior - o lúdico -, constitui-se pela concretização do corporal, da espontaneidade, do sentido de humor, da alegria e do prazer expressos por meio dos movimentos e das ações do sujeito. Não obstante o avanço sugerido pelos PCN (Brasil, 1998), Santin (1993), comentando a desportivização das práticas corporais, salienta que "brincar tornou-se uma atividade dependente dos conhecimentos científicos, dos segredos técnicos e dos interesses econômicos" (p. 104), valendo mais a vitória do que o prazer de jogar. E frisa ainda que "os comportamentos lúdicos são tão importantes quanto o comer e o beber" (p. 104).

Parece que interesse e desinteresse se cruzam quando o Jogo está em questão. Neste sentido, Santin (1994) pergunta: por que o Jogo? E comenta que o Jogo, apesar de não ser a única, é uma excelente forma de compreender as estruturas sociais, porque contempla a ideia de liberdade e de espontaneidade, de acaso, sem pré-determinismos. Desse modo, o Jogo configura-se um código corporal não verbal, que vai irradiando sentidos não determinados; desfruta, portanto, de um estatuto que corresponde ao da autonomia da obra de arte (Wisnik, 2008).

Neste contexto, para Soares e colaboradores (1992), o ser humano inventou o brincar, "um ato em que sua intencionalidade e curiosidade resultam num processo criativo para modificar, imaginariamente, a realidade e o presente" (p. 64). Conceitos como intencionalidade, expressão, espontaneidade, lúdico, liberdade, entre outros, conferem ao Jogo, na sua forma original, um enfoque primordial em direção ao entendimento significativo do movimento humano.

Também Cunha (2009), ao refletir sobre a problemática do movimento humano, vai dizer que a dimensão lúdica do humano (homo-ludens) é uma das maiores invenções da humanidade. Com o homo-ludens, o ser humano chamou a si três sentidos para a existência: brincar, jogar e competir. Nestes sentidos podemos ver o homem-todo já "cantado" pelos Gregos: o homem-todo constitui-se como o sensível, o inteligivel, o imanente e o transcendente. 
2. O JOGO, O MOVIMENTO HUMANO E A TEORIA DO SE-MOVIMENTAR

A concepção dialógica do movimento humano procura um entendimento não mecânico do movimento. Esta teoria orienta-se na relação entre ser humano e mundo por meio da ação que é, exatamente, o diálogo que o ser humano desenvolve com o mundo através do seu se-movimentar. Este se-movimentar, para Tamboer (1979), "é junto com o pensar e falar, entre outras ações, uma das múltiplas formas nas quais a unidade primordial do ser humano com o mundo se manifesta... o se-movimentar é a forma de um agir original do ser humano, por meio da qual ele se garante como ser-nomundo e na qual - neste agir - ele mesmo, como sujeito, e o mundo, como sua contraface imaginária, adquirem contornos reais" (p. 16). Também Trebels (2006) vai referir que o se-movimentar é uma expressão que diz o ser humano consigo mesmo, com os outros e com o mundo. Para estes dois autores, o Jogo emerge como conteúdo dialógico imanente e transcendente.

Por sua vez, o Jogo, segundo Huizinga (2001), é

uma atividade ou ocupação voluntária, exercida dentro de certos e determinados limites de tempo e espaço, segundo regras livremente consentidas, mas absolutamente obrigatórias, dotadas de um fim em si mesmo, acompanhado de um sentimento de tensão e de alegria e de uma consciência do ser diferente da vida cotidiana. (p. 33)

Podemos perceber que o poder da ação ou, ainda, da intenção de agir recai sobre o sujeito desta ação. Tanto no Jogo como na concepção dialógica do movimento humano, o ser humano é livre para agir de forma original e voluntária. As regras existem, podendo ser criadas e modificadas pelos envolvidos, originando situações/condições para melhor interagirem consigo mesmos, com as pessoas e com o mundo. Queremos enfocar aqui o Jogo como movimento humano, inserido no mundo de movimento das pessoas e que se faz conteúdo da Educação Física escolar.

Ao se-movimentar, as pessoas questionam o mundo, as outras pessoas e as coisas com as quais compartilham a existência. Esses questionamentos não são (só) direcionados pela lógica da racionalidade científica. $O$ sujeito se permite validar aspetos que são da esfera da sensibilidade, do sentimento, da emoção e do autoconhecimento, o que permite a libertação de intencionalidades que permeiam toda a relação existente entre o ser humano e o mundo.

Esta intencionalidade habita o Jogo que, por si só, tem uma conotação de liberdade, que conduz o ser humano a um estado de euforia, mostrando que a intencionalidade do sujeito somente pode existir quando este está livre das pressões e de resultados que lhe são impostos. A intencionalidade não significa apenas o ser humano dirigir a atenção ao objeto, mastambém estar atento, de forma pré-consciente e préracional, a todas "as peças do cenário" que o ser humano configura com o mundo. Desta forma, Gordijn (1968) comenta que o se-movimentar significa, sobremaneira, a atualização dos significados motores em situações concretas, correspondendo à realização de movimentos a partir de possibilidades individuais. Estar em situação de Jogo permite que cada indivíduo possua uma gama cultural que distingue as pessoas umas das outras, porque se trata de uma atividade em que o inusitado e a imprevisibilidade permeiam as ações.

O Jogo e sua natureza lúdica permitem uma relação do sujeito com o mundo de forma interpretativa e, portanto, significativa. Nesse sentido, é capaz de facilitar a ocorrência simultânea da relação dialógica entre 
desenvolvimento e aprendizagem.

Podemos perceber que tanto no semovimentar do homem como no Jogo, as relações que os envolvem devem receber um destaque interdisciplinar e integral. O ser humano se-movimenta como um ser unitário e total. A intencionalidade do movimento humano gera um sentimento global de significação que envolve todas as esferas do ser humano em movimento em direção ao mundo. Esse sentimento de integração é proporcionado pela forma própria que o ser humano criou no seu se-movimentar e que vai oportunizar o conhecimento do mundo e manter relações de forma significativa. O Jogo não é prerrogativa apenas da Educação Física, já que jogos e brincadeiras permeiam toda a ação humana, desde os primeiros indícios de existência humana. O Jogo pode ser vinculado à cultura, à ordem social e aos interesses ideológicos e, portanto, pode ser material de pesquisa da linguística, da história, da sociologia, da filosofia e da matemática, para citar somente algumas áreas.

Kunz (1991) enfatiza que o se-movimentar, entendido como diálogo entre ser humano e mundo, envolve sempre o sujeito e a sua intencionalidade. É através da intencionalidade que o se-movimentar se constitui como sendo significativo: "o movimento humano é fundado na intencionalidade” (p. 175). É essa intencionalidade que procura superar a relação dualista de sujeito cognoscente e objeto cognoscível. Tudo é uma totalidade, ambos os fatores estão intimamente relacionados e interligados, sendo impossível existir um sem o outro. Nesta relação, não podemos distinguir nada no mundo como sendo objeto ou sujeito, tudo pertence a um mundo de relações intencionais. Nesse sentido, Kunz (1991) defende que o "sentido/significado é assim constituído na relação homem/ mundo, e não pode ser localizado somente no sujeito ou no(s) objetos(s)" (p. 175).

Com efeito, comentando a relação do mundo com o sujeito, o Jogo está na gênese do pensamento, da descoberta de si mesmo, da possibilidade de experimentar, de criar e de transformar o mundo, pelo fato de comportar o lúdico no seu fazer-se. A ideia de Jogo é central para a civilização. O Jogo, segundo Huizinga (2001), vem como uma categoria absolutamente primária da vida, tão essencial quanto o raciocínio (homo sapiens) e a fabricação de objetos (homo faber). O ser humano que brinca não substitui o homo sapiens, que sabe e que raciocina, mas coloca-se ao lado e um pouco abaixo deste, mais ou menos na mesma categoria do homo faber, aquele que trabalha. O caráter de ficção é um dos elementos constitutivos do Jogo, no sentido de fantasia criativa, da imaginação. $\mathrm{E}$, ao contrário do que muitas pessoas podem admitir, é algo muito sério e necessário, além de ser um direito. Enquanto o Jogo se realiza/ ocorre, as regras que regem a realidade quotidiana ficam suspensas.

Pensamos que o Jogo, entendido como categoria primária da vida, pode ser mais bem compreendido no mundo pré-reflexivo, ou ainda pré-consciente, tendo em vista que ele é continuamente constituído através das nossas experiências. Este mundo é o mundo vivido; o mundo que nos proporciona uma oportunidade ímpar para sermos quem realmente somos, com nossas emoções, sentimentos, alegrias e frustrações. É nele que podemos ser autênticos e criar formas intencionais e originais de nos relacionarmos com o mundo e de transformálo ao nosso modo. Nesse universo, não existem formas de movimentos pré-estabelecidas, mas construídas livremente baseadas na subjetividade.

O mundo vivido, ou ainda mundo da vida que é a tradução da palavra alemã Lebenswelt-, é um termo utilizado por Husserl para 
designar o mundo da experiência humana que é considerado antes de qualquer tematização conceptual. Segundo Japiassú e Marcondes (1996), o mundo da vida é o que se aceita como dado, como pressuposto, e que constitui nossa experiência quotidiana: "trata-se do real em seu sentido pré-teórico e pré-reflexivo” ( $p$. 190).

Neste envolvimento, Surdi (2010) refere que a ciência moderna e a sua consequente forma de quantificar a realidade tornaram-se alvo de muitas críticas, por ignorar inúmeras questões significativas que fazem parte do mundo da vida. O mundo em que vivemos produz uma gama de possibilidades e diversidades de sons, imagens, cores, sabores, cheiros e muito mais; no entanto, compreendidos como qualidades secundárias pela ciência. Estas possibilidades fazem parte do mundo "irreal", enquanto o mundo real é observado, analisado, controlado pelo conhecimento científico da natureza. Dessa forma, o mundo da ciência é sempre considerado o verdadeiro, ao passo que aquele que vivenciamos de forma direta, o das possibilidades e diversidades, é compreendido como ilusório e insignificante.

As visões mecanicistas do movimento humano, baseado nas análises biomecânicas, interpretam o movimento humano para construir padrões de movimento eficazes para determinado gesto técnico, seja no desporto ou outra atividade de rendimento. Este tipo de entendimento não leva em consideração fatores essenciais e cruciais para que o movimento humano seja um fator importante na vida das pessoas com possibilidade de conhecer o mundo e modificá-lo. As diferenças individuais e toda a cultura que cada pessoa possui são excluídas. O sujeito pensante, que brinca, que questiona a realidade e produz cultura fica de fora deste movimento padronizado externamente. O mundo vivido é a individualidade que caracteriza cada ser humano em movimento.
Apenas neste contexto o lúdico pode ter o seu devido valor. É no mundo vivido que estas manifestações originais e subjetivas podem ser entendidas como significativas e importantes para a vida das pessoas.

A teoria do se-movimentar humano baseiase em princípios que procuram resgatar o significado/ sentido humano do movimento. Para isso, as interpretações devem basearse, principalmente, em três dimensões: primeiramente, no ator do movimento, ou seja, no sujeito da ação, pois todas as ações de movimento são produzidas por atores, que são os descobridores das condutas motoras; depois, numa situação concreta a que as ações de movimento estão vinculadas, situação que, além do ambiente físico, deve contemplar os contextos sociais e culturais onde os movimentos serão realizados; e, por fim, um sentido/ significado que orienta a ação e a estruturação do movimento.

Esse sentido/significado deve ser constituído pela cultura de movimento das pessoas, através do seu mundo vivido. Huizinga (2001) entende o Jogo como algo de irracional que, em alguns momentos, foge do controle e não consegue ser aprisionado na racionalidade; é quando provoca o desligamento do quotidiano para introduzir um mundo de faz-de-conta, de ficção. Esse mundo é o vivido, antes de ser "representado" pela ciência.

Dessa forma, podemos perceber que, realmente, existe um diálogo entre o ser humano e o mundo, através do movimento. Neste semovimentar, a pessoa participa ativamente da ação e, com isto, consegue entender o mundo à sua volta, por meio da experimentação. Nesta relação entre o ator, a situação e o significado, surge um momento de troca, que possibilita uma assimilação da ocasião que proporciona um entendimento da pessoa que se movimenta sobre aquele momento da realidade: o "semovimentar é o movimento próprio do ser 
humano; movimento que deve ser interpretado de forma consciente, e sempre a partir das referências anteriores apresentadas" (Kunz, 2005, pp. 385-386).

A cultura mostra a presença ativa do fator lúdico como criador de muitas formas fundamentais da vida social. Pode-se dizer, então, que a fase primitiva da cultura é o Jogo. Segundo Huizinga (2001), é no Jogo e pelo Jogo que a civilização surge e se desenvolve. Portanto, o Jogo é um fenómeno cultural e não biológico, pode ser estudado sob uma perspectiva histórica, sociológica, antropológica, psicológica e científica.

\section{O LÚDICO - O BRINCAR E O JOGAR:} FATORES QUE CARACTERIZAM O MOVIMENTO HUMANO SIGNIFICATIVO

O lúdico inclui o brincar, o jogar e o competir (Cunha \& Gonçalves, 2015). No brincar, a intencionalidade do ser humano é maximizada pelo fato de ele ser o ator de sua ação. No brincar está presente a imaginação, o sonho, e a não existência de regras. No Jogo também são exploradas as formas de criação e invenção, mas apresenta um outro aspeto estruturante: as regras. Só há jogo quando há regras. Quer no brincar, quer no jogar (que se complementam), as condutas partem do sujeito, que busca construir sentidos individuais e relacionais. Existe um respeito pelas diferenças, no sentido em que os papéis não são impostos externamente, mas discutidos no grupo. Assim, todo o ser humano tem o poder de mudar o mundo e, claro, como dissemos anteriormente, de se mudar a si mesmo. $\mathrm{O}$ brincar e o jogar possibilitam que as pessoas se entreguem totalmente à atividade proposta. A ludicidade (pelo brincar e jogar) fornece um impulso para que este ato seja intrínseco e cheio de significações.

Enfatizando o Jogo (que anima a nossa reflexão), Huizinga (2001) comenta que a essência do Jogo reside na sua intensidade, fascinação e capacidade de excitar, expressando-se através do ritmo e harmonia, evidenciando o elemento lúdico em toda a sua análise e interpretação. Este conceito mostra o Jogo como um fenómeno cultural, fixado na nossa tradição, com raízes em todo o processo de humanização do ser humano, valorizado pela ludicidade e pela estética. Para Huizinga (2001), “a vivacidade e a graça estão originalmente ligadas às formas mais primitivas do jogo. É neste que a beleza do corpo humano em movimento atinge seu apogeu" (p. 9).

Para Gordijn (1968), o se-movimentar relaciona-se com fatores intencionais intrínsecos e com a percepção de objetos e fenómenos do mundo. Salienta ainda que os laços entre beleza e jogo se estruturam através de uma linguagem subjetiva e intersubjetiva, fazendo do movimento uma manifestação estética profundamente humana.

Nesse sentido, Trebels (2006) afirma que:

Neste conceito, os significados subjetivos, ou seja, incluídos intencionalmente, e os significados objetivos, isto é, os pré-dados e percebidos no mundo, inter-relacionam-se organicamente. Os significados motores não são só produção de sentidos individuais (apenas como uma intenção de movimento) nem, tampouco, unicamente o resultado de experiências com as qualidades intrínsecas dos objetos (o mundo percebido no ser-assim), mas, sim, uma delimitação e mútua complementaridade dessas perspectivas. Ambas se encontram numa relação de nexos que são coincidentes. (p. 41)

O nosso mundo é sempre um mundo vivido. É nele que nossas possibilidades de semovimentar se tornam humanas, significativas e belas. As nossas experiências originais são fundamentais para que a nossa compreensão de mundo seja significativa. Temos que agir e participar ativamente na relação que temos 
com este mundo, relação essa que se dá, muitas vezes, pelo movimento, e esse movimento tem que ser inventivo e individual, pois todas as pessoas são diferentes. E, por serem diferentes, devem compreender o mundo a seu modo e dessa forma criar o seu se-movimentar, que proporciona uma comunicação com o mundo também significativa.

Esse poder de criação motora está direcionado ao sujeito que pratica o movimento e não ao movimento propriamente dito. $\mathrm{O}$ poder proporcionado ao sujeito da ação permite que ele participe e controle todas as suas ações de movimento. A intervenção da subjetividade nesse processo é indispensável, pois ela adquire características sociais que se desenvolvem por meio das vivências individuais. Dessa forma, Kunz (1994) vai fazer o elogio da Educação (Física) como caminho crítico, objetivo e subjetivo, capaz de elevar o ser humano emancipado, crítico e livre. A subjetividade é a nossa forma verdadeira de conhecer o mundo. O mundo e as coisas que o habitam não existem definidas "em si", mas são constituídas de possibilidades infinitas de agir, perceber, sentir, entre outras. A subjetividade de cada pessoa é o que traduz o lado humano de ser o que se é. As vivências subjetivas do movimento humano são fundamentais para as crianças e baseiamse na cultura de movimento de cada um, sem parâmetros nem modelos. As experiências individuais proporcionam a naturalidade e a originalidade desse movimento, o que os faz significantes; assim a criança toma consciência do seu próprio movimento, que traduz a sua forma autêntica de desvendar o mundo.

Com muita similaridade, Huizinga (2001) realça as características fundamentais do Jogo como sendo um ato voluntário, que se concretiza como evasão da vida real, com orientação própria, ocorrendo dentro de limites de tempo e de espaço, e criando a ordem através de uma perfeição temporária e limitada. Contudo, não se deve esquecer o papel fundamental das regras de um Jogo, "e não há dúvida de que a desobediência às regras implica a derrocada do mundo do jogo" (Huizinga, 2001, p. 14). O autor, assim, aborda mais um conceito de Jogo, como sendo:

uma atividade livre, conscientemente tomada como "não séria" e exterior à vida habitual, mas ao mesmo tempo capaz de absorver o jogador de maneira intensa e total. É uma atividade desligada de todo e qualquer interesse material, com a qual não se pode obter lucro, praticada dentro de limites espaciais e temporais próprios, segundo uma certa ordem e certas regras. (p.16)

Fica evidente que, tanto no Jogo como na realização do movimento humano significativo, o praticante se entrega por inteiro. Tais atividades tornam-se parte do sujeito. Esta intencionalidade que tem $o$ poder lúdico proporciona $o$ desligamento do mundo da racionalidade, partindo para o mundo da vida ou vivido, onde as nossas experiências são postas em jogo, expressadas e exteriorizadas. A possibilidade de criação é oportunizada pelo sentido de abertura que este mundo pré-reflexivo nos propõe. Nada é definido a priori, tudo é criado pelos sujeitos, baseados nas suas subjetividades.

A cultura vivida pelo ser humano é de grande importância no processo de conhecimento e compreensão do mundo; é o que proporciona que ele se mostre como realmente é. Como refere Kunz (1994):

Manter o ser humano distante ou afastado do real e do sensível à cultura, do seu modo de agir, pensar e sentir é fragmentar sujeito e conhecimento, é evitar o conhecimento reprimido, a curiosidade e a paixão pelo mundo, e pelo outro, é mantêlo na ignorância. Pode-se facilmente identificar onde e quando esses momentos acontecem na escola (embora a escola não seja a única instância em que isto acontece)... $\mathrm{Na}$ proibição do falar; 
no desencorajamento de expressões de afeto, ou de emoção, como o riso e o choro; pela censura a atitudes infantis; pela separação em meninos e meninas, e principalmente pelo controle e disciplinamento do seu se-movimentar. (p. 114)

A realidade deve ser construída pelo sujeito, através da sua relação vivida com o mundo. Esta relação deve passar por uma reflexão rigorosa do sujeito da ação, que busca o melhor para si e para o mundo em que vive. As decisões do se-movimentar devem ser tomadas pelo ator do movimento, através das suas experiências, levando em consideração critérios individuais como velocidade, força, ritmo e outras qualidades humanas que são próprias de cada pessoa.

$\mathrm{Na}$ busca pelo entendimento do movimento humano como significativo, Santin (1987) salienta que existem várias possibilidades de compreender o movimento humano. Primeiramente, ele classifica-o como uma ação motora, baseada, como dissemos anteriormente, nos princípios e nas leis da física e da mecânica. Aqui podemos citar os movimentos desenvolvidos biomecanicamente com intenção de melhorar o rendimento humano e, também, os movimentos destinados à melhoria na realização de determinada modalidade desportiva. Esta visão está ligada à funcionalidade mecânica do movimento humano. Outra possibilidade de compreensão do movimento humano é a locomoção de um lugar para outro, que pode igualar o ser humano a qualquer animal. Movimentos como correr, saltar e andar são entendidos, aqui, como simples formas de movimento que passam de geração a geração. $\mathrm{O}$ terceiro ponto de entendimento do movimento humano caracteriza-o como fonte de energia e produtividade. O trabalho do ser humano produz um gasto calórico que é fundamental para que muitas tarefas sejam realizadas e os objetivos alcançados.

Como última forma de perceber o movimento humano, ele pode ser entendido como linguagem ou ainda como capacidade expressiva. O ser humano expressa-se através dos seus movimentos, pela sua forma de se posicionar, de olhar, de gesticular: "o corpo humano é fala e expressão" (Santin, 1987, p. 34). Essa forma significativa de entender o movimento humano é sempre intencional e cheia de sentido. O Jogo, como forma de beleza, torna-se arte, porque se expressa no mundo de forma direta eimprevisível; através dos seus movimentos, ele fala, discute e reflete sobre o mundo. Esse movimento significativo e expressivo é o que distingue o ser humano no mundo e lhe proporciona o poder de transformá-lo a seu modo.

A ludicidade (brincar, jogar, competir) faz-se presente no processo de humanização do ser humano, no qual se expressam, principalmente, os sentimentos de prazer e de alegria, servindo como estímulo primordial e fonte de inspiração para os diversos jogos. Segundo Santin (1994), "a ludicidade se constitui por uma atmosfera de total liberdade e autonomia" (p. 28). Para o autor, a ludicidade surge da vontade de "querer brincar", de forma espontânea e surpreendente. Salienta, ainda, que a ludicidade "não pode ser apreendida pela palavra, mas pela fruição. O comportamento lúdico é vivência, isto é, é fruição" (Santin, 1994, p. 28).

Baseados nessa ótica, abordamos o movimento humano significativo e o modo como o Jogo pode ser entendido como uma real possibilidade de descoberta do mundo pelo ser humano, através do diálogo que o ser em movimento faz consigo, com o outro e com o mundo. Compreender o mundo pela ação quer dizer utilizar o movimento próprio do ser humano em direção ao mundo, mundo este que é sempre um mundo vivido, aquele pré-reflexivo, onde utilizamos nossas experiências e vivências motoras mais originais, impulsionadas pela intencionalidade. $\mathrm{O}$ se-movimentar consiste nas experiências motoras significativas e individuais, 
onde o indivíduo busca um contato com o mundo. Este contato deve ser entendido como dialógico e, para que isto aconteça, o ser humano deve ser participativo, criativo e produzir intencionalmente uma comunicação para que o diálogo se efetive e, assim, compreender este complexo mundo e ser compreendido por ele. O Jogo, entendido como expressão primordial do ser humano, carrega o potencial lúdico que fornece as possibilidades essenciais para que o ser humano em seu se-movimentar desenvolva este diálogo com o mundo.

\section{O SE-MOVIMENTAR PROPORCIONA} UM MUNDO DE SIGNIFICAÇÃO E SUA APROPRIAÇÃO DÁ-SE EM TRÊS ETAPAS

Para Tamboer (1979), o movimento humano intencional pode ser adquirido de três formas diferentes. O primeiro é a forma direta, onde a transcendência acontece na base da intencionalidade espontânea das pessoas como uma ação não pensada. Esta forma está relacionada com o plano pré-reflexivo, ou seja, as respostas são fornecidas livre e espontaneamente ao mundo. Como exemplo, Kunz (1991) recorda os primeiros contatos de uma criança com a bola. Ela sabe o que fazer com a bola e, gradativamente, vai brincando através do chutar, rebater, com isto vai dialogando com o mundo, construindo o seu mundo de significações.

A segunda forma é a apreendida. Ela surge pela aprendizagem, ou ainda pela intencionalidade que se desenvolve a partir da ideia de imagem do movimento. Nessa forma, a questão principal é fornecer pistas sobre a ideia do movimento para que o problema seja resolvido. Não se quer valorizar a imitação, mas simplesmente mostrar parcialmente a intenção de que o movimento pode ser executado para se chegar a um fim. Este movimento, segundo Tamboer (1979), deve ser aprendido através de uma estratégia, denominada “imitação de uma intenção” (p. 134).
A terceira forma é a criativa/inventiva, que surge da intencionalidade inventiva e criativa por parte de cada um. A transcendência do mundo é feita a partir da criação e invenção. $O$ ser humano explora e constitui o mundo com novos significados/ sentidos que lhe fornecem uma maior compreensão-de-mundo. A partir desta compreensão, o ser humano adquire capacidades para mudar o mundo situacional em que vive e, consequentemente, mudar-se a si próprio.

\section{CONSIDERAÇÕ ES FINAIS}

Podemos perceber que a relação entre o Jogo e o movimento humano significativo é bastante ampla. O Jogo como atividade de movimento que é utilizado pela Educação Física deve ter como fator fundador o sujeito da ação, que está no centro do processo de realização deste movimento. Este movimento, por ser subjetivo, é uma ação intencional que oportuniza ao indivíduo ter o poder sobre o seu se-movimentar. Os padrões de movimento existem, mas o que importa nesta ótica são as pessoas movimentando-se livremente, o que caracteriza o Jogo e, consequentemente, o componente lúdico. A ludicidade só acontece num espaço livre, onde a criação é motivada e a atividade é feita por prazer.

O lúdico, com seus constituintes - brincar, jogar, competir -, ultrapassa as necessidades que temos de forma imediata na vida diária. Ele possui um valor em si mesmo, constituindo assim uma realidade própria. Por isso, quando estamos realizando uma atividade realmente lúdica, envolvemo-nos de tal forma na atividade que ela própria nos satisfaz por inteiro. Doamo-nos por completo, e é exatamente nesse momento que percebemos muito do que realmente somos e da capacidade que possuímos. O nosso eu revela-se através do lúdico, caracterizado pela realização de atividades significativas; dentre 
elas o se-movimentar, que oportuniza um conhecimento de si, a partir das formas de se relacionar com o mundo, momento em que podemos nos expressar de forma autónoma e espontânea.

Neste mundo vivido, o nosso movimento não é entendido como um simples deslocamento físico num determinado espaço e tempo, como o mundo da ciência nos procura mostrar. É muito mais complexo, envolve expressão, arte, criação, alegria e prazer. Surge das nossas intencionalidades, que proporcionam um contato dialógico com o mundo, possibilitando, assim, que tanto o sujeito da ação como o mundo sejam transformados mutuamente. É o nosso movimento próprio, que vem das nossas individualidades e das nossas necessidades como sujeitos autónomos.

O Jogo, como atividade dessa dimensão lúdica, inclui elementos essenciais para o ser humano. O Jogo pode representar para os sujeitos uma "segunda natureza", na medida em que consegue permanecer vigilante $\mathrm{e}$ atento às necessidades de prazer, alegria e satisfação das pessoas. O Jogo, como atividade, conteúdo e conhecimento da Educação Física escolar pode possibilitar a manifestação do movimento humano em toda a sua amplitude. Assim, os movimentos que configuram as situações de sujeitos em jogo na escola não precisam estar necessariamente orientados segundo os padrões de referência dos interesses da quantificação objetiva. Em ação, o binómio movimento humano e jogo permitem momentos de expressão da subjetividade, que foi esquecida nos dias de hoje pelo predomínio dos ditames da racionalidade científica.

Esta realidade também pode ser entendida na Educação em geral. Temos tido uma educação centrada no ler, escrever, contar, e agora nas técnicas e tecnologias. Falta-nos uma educação que tenha um sentido lúdico pleno. Quando falamos no sentido lúdico pleno estamos a falar numa educação (real e simbólica) do brincar, do jogar e do competir (Cunha, 2013). A saber:

O brincar é o "início", um início absoluto... O brincar é a raiz, a potência, a luz inicial. $\mathrm{O}$ brincar é uma manifestação fenomenológica, uma intencionalidade fenomenológica que vem de dentro. E por isso o brincar é do campo da imaginação, do sonho, do sensível, do sentimento. É no brincar que encontramos a verdadeira liberdade - a liberdade livre.

O jogar é o "meio"... No jogar há uma evolução do sentido fenomenológico para uma certa racionalidade. $\mathrm{O}$ jogar vai organizar a brincadeira (a "desordem" da brincadeira), dando-lhe ordem. O ser humano precisa de ordem. A forma de dar ordem foi a invenção e a estipulação de regras. A regra é a grande invenção do jogar. Com o jogar e com a regra, vai nascer a moral e a ética.

O competir é o "fim”... A competição tem um triplo caráter: é fenomenológica - a competição também faz parte do início -, é reino animal e, com ela, a competição emerge por questões de sobrevivência, território, alimento, reprodução, ...; é racional - a competição utiliza regras, mas também estratégias, táticas, pensamento, intuição...; é ir para a frente, para diante... A competição é uma oportunidade de ser mais. A competição tem em si/ traz em si outras palavras importantes para o ser humano: trabalho, esforço, resiliência, dedicação, regulamentos, rendimento, eficácia, treino, repetição, técnica, afirmação e superação, mas também o belo, o prazer, a esperança, a utopia, a ética, a estética....

Precisamos de uma educação com as características do brincar, do jogar e do competir. Falta-nos uma educação para o Ser Humano do campo do sensível, do inteligível, do imanente e do transcendente. 


\section{REFERÊ NCIAS}

Brasil. (1998). Parâmetros curriculares nacionais: Educação física. Brasília, DF: $\mathrm{MEC} / \mathrm{SEF}$.

Charlot, B. (2009). Ensinar a educação física ou ajudar o aluno a aprender o seu corposujeito? In H. Dantas Júnior, R. Kunh, \& S. Dorenski (Orgs.), Educação física, esporte e sociedade: Temas emergentes (pp. 231-246). São Cristóvão, SE: UFS.

Cunha, A. C. (2009). As brincadeiras ou a verdade existencial. In I. C. Condessa (Org.), (Re)aprender a brincar: Da especialidade à diversidade (pp. 85-91). Ponta Delgada: Nova Gráfica.

Cunha, A. C. (2013). A Educação Física na Europa e no Brasil: Um sentido comum que mostra uma identidade universal. Revista Em Aberto, 26(89), 81-93.

Cunha, A. C., \& Gonçalves, S. (2015). A criança e o brincar como obra de arte: Analogias e sentidos. Santo Tirso: Whitebooks.

Ferry, L. (1995). L'homme-dieu ou le sens de la vie. Paris : Grasset.

Gómez, A. I. P. (1998). As funções sociais da escola: Da reprodução à reconstrução crítica do conhecimento e da experiência. In J. G. Sacristán, \& A. I. P. Gómez, Compreender e transformar o ensino (pp. 13-26). Porto Alegre, RS: Artmed.

Gordijn, C. C. (1968). Inleiding tot het bewegingsonderwijs [Introdução à educação física]. Baarn: Krips Repro.

Huizinga, J. (2001). Homo ludens: O jogo como elemento da cultura. São Paulo: Perspectiva.

Japiassú, H., \& Marcondes, D. (1996). Dicionário básico de filosofia. Rio de Janeiro: Jorge Zahar Editor.

Kunz, E. (1991). Educação física: Ensino \& mudanças. Ijuí, RS: Unijuí.

Kunz, E. (1994). Transformação didáticopedagógico do esporte. Ijuí, RS: Unijuí.

Kunz, E. (1995) A relação teoria/prática no ensino/pesquisa da educação física. Motrivivência, 7(8), 46-54.
Kunz, E. (2005). Se-Movimentar. In F. J. González, \& P. E. Fensterseifer (Eds.), Dicionário crítico de educação física (pp. 383-386). Ijuí, RS: Unijuí.

Moreira, E. C., \& Grunennvaldt, J. T. (2016). Contra a idealização da educação física e a favor de sua prática social: Porque o conceito e a identidade da educação física são construídos na escola. In J. L. Anjos, \& F. Q. Almeida (Orgs.), Educação física, corpo e tradição: Ojogo das comunidades tradicionais (pp. 59-80). Curitiba, PR: Appris.

Santin, S. (1987). Educação física: Uma abordagem filosófica da corporeidade. Ijuí, RS: Unijuí.

Santin, S. (1993). Educação física - Outros caminhos. Porto Alegre, RS: EST/ESEFUFRGS.

Santin, S. (1994). Educação física: Da alegria do lúdico à opressão do rendimento. Porto Alegre, RS: EST/ESEF-UFRGS.

Soares, C. L., Taffarel, C. N. Z., Varjal, E., Castellani Filho, L., Escobar, M. O., \& Bracht, V. (1992). Metodologia do ensino de educação física. São Paulo: Cortez.

Surdi, A. C. (2010). Educação física e o movimento humano significativo: Uma possibilidade fenomenológica. Videira, SC: Êxito.

Tamboer, J. W. I. (1979). Sich-bewegen - Ein dialog zwischen mensch und welt [Semovimentar - Um diálogo entre ser humano e mundo]. Sportpädagogik, 3(2), 60-65.

Trebels, A. (2006). A concepção dialógica do movimento humano: Uma teoria do semovimentar. In E. Kunz, \& A. Trebels (Orgs.), Educação física crítico-emancipatória: Com uma perspectiva da pedagogia alemã do esporte (pp. 23-48). Ijuí, RS: Unijuí.

Wisnik, J. M. (2008). Veneno remédio: O futebol e o Brasil. São Paulo: Companhia das Letras. 


\section{ELEMENTS OF PHENOMENOLOGY AS ONE OF THE POSSIBILITIES OF UNDERSTANDING THE GAME AS A SIG IFICANT HUMAN MOVEMENT}

\section{Abstract}

The essay aims to reflect on Game as one of the dimensions of the ludic (along with playing and competing). The reflection will praise Game as an end in itself, contradicting the idea of the Game as a medium, an instrument at the service of theoretical and didactic models. The Game is able to provide a significant human movement to those who play, founded on the dialogical conception of movement. In this sense, some notes that make Game an essential part of Physical Education (education in general) and significant human movement will be presented; among them, we can advance subjectivity, creativity, dream, willpower, possibility, freedom, ... as constituents of the human being.

KeYwords: Game; Significant human movement; Subjectivity; Ludic

\section{ELEMENTOS DE LA FENOMELOGIA COMO UNA DE LAS POSSIBILIDADES DE ENTENDER EL JUEGO COMO UN MOVIMIENTOHUMANO SIGNIFICATIVO}

\section{RESUMEN}

El presente texto tiene como objetivo reflexionar sobre el Juego como una de las dimensiones del lúdico (junto al juego y el competir). La reflexión va a hacer el elogio al Juego como un fin en sí mismo, contrariando la idea del Juego como un medio, un instrumento al servicio de modelos teóricos y didácticos. El Juego es capaz de prestar a quienes juegan un movimiento humano significativo, fundado a partir de la concepción dialógica de movimiento. En este sentido se presentarán algunos apuntes que hacen del Juego una parte esencial de la Educación Física (de la educación en general) y del movimiento humano significativo; de entre ellos, podemos citar la subjetividad, la creatividad, el sueño, la voluntad, la posibilidad, la libertad, ... como constituyentes del ser humano.

Palabras Clave: Juego; Movimiento humano significativo; la Subjetividad; Lúdico

\footnotetext{
${ }^{\text {I }}$ Instituto de Educação, Centro de Investigação em Estudos da Criança, Universidade do Minho, Portugal. ORCID: 00000001-9652-9870

${ }^{\text {II }}$ Departamento de Educação Física, Centro de Ciências da Saúde, Universidade Federal de Santa Catarina, Florianópolis, Brasil.

III Departamento de Educação Física, Centro de Ciências da Saúde, Universidade Federal de Santa Catarina, Florianópolis, Brasil.

Iv Centro de Educação Física e Desportos, Universidade Federal de Santa Maria, Brasil.

v Departamento de Teoria e Fundamentação, Faculdade de Educação Física, Universidade Federal de Mato Grosso, Brasil.
}

Toda a correspondência relativa a este artigo deve ser enviada para:

Evando Carlos Moreira

Universidade Federal de Mato Grosso, Departamento de Teoria e Fundamentação,

Faculdade de Educação Física

Av. Fernando Corrêa da Costa, 2367 - Boa Esperança, Cuiabá - MT, 78060-900

Recebido em março de 2017

Brasil.

E-mail: ecmmoreira@uol.com.br 